OPEN ACCESS

Edited by:

Philippe Saas,

Etablissement Français du Sang

$B F C$, France

Reviewed by:

Britta Christina Urban,

Liverpool School of Tropical

Medicine, UK

Arnaud Millet,

INSERM, France

*Correspondence:

Régis Josien

regis.josien@univ-nantes.fr

Specialty section:

This article was submitted to Inflammation,

a section of the journal

Frontiers in Immunology

Received: 03 November 2016

Accepted: 20 January 2017

Published: 09 February 2017

Citation:

Braudeau C, Néel A, Amouriaux K, Martin JC, Rimbert M, Besançon A,

Giraudet S, Terrien C, Aliaga M, Salabert-Le Guen N, Hémont C, Hamidou M and Josien R (2017) Dysregulated Responsiveness of Circulating Dendritic Cells to Toll-Like

Receptors in ANCA-Associated Vasculitis.

Front. Immunol. 8:102. doi: 10.3389/fimmu.2017.00102

\section{Dysregulated Responsiveness of Circulating Dendritic Cells to Toll- Like Receptors in ANCA-Associated Vasculitis}

\author{
Cécile Braudeau 1,2,3, Antoine Née/,3,5, Karine Amouriaux ${ }^{1,6}$, Jérôme C. Martin ${ }^{1,2,3,4}$, \\ Marie Rimbert'1,2,3, Audrey Besançon', Stéphanie Giraudet', Caroline Terrien', \\ Marine Aliaga ${ }^{1}$, Nina Salabert-Le Guen ${ }^{1,3,6}$, Caroline Hémont ${ }^{1,2,3}$, Mohamed Hamidou ${ }^{3,4,5}$ \\ and Régis Josien ${ }^{1,2,3,4,6 *}$
}

'CIMNA, Laboratoire d'Immunologie, CHU Nantes, Nantes, France, ${ }^{2}$ Institut de Transplantation-Urologie-Néphrologie (ITUN), CHU Nantes, Nantes, France, ${ }^{3}$ Centre de Recherche en Transplantation et Immunologie (UMR1064), INSERM, Université de Nantes, Nantes, France, ${ }^{4}$ Faculté de Médecine, Université de Nantes, Nantes, France, ${ }^{5}$ Service de Médecine Interne, CHU Nantes, Nantes, France, ${ }^{6}$ LabEx Immunotherapy Graft Oncology (IGO), Nantes, France

Objective: Dendritic cells (DCs) are critical effectors of innate and adaptive immunity playing crucial roles in autoimmune responses. We previously showed that blood DC numbers were reduced in autoimmune antineutrophil cytoplasmic autoantibody-associated vasculitis (AAV). Here, we assessed toll-like receptor (TLR) responsiveness of blood DCs from patients with granulomatosis with polyangiitis (GPA) or microscopic polyangiitis (MPA).

Methods: Blood samples from healthy controls (HCs), GPA, or MPA patients, without treatment, during acute phase (AP) or remission phase (RP) were analyzed. Cytokine production by DCs and T cells was assessed on whole blood by flow cytometry after TLRs or polyclonal stimulation, respectively.

Results: We first showed that GPA and MPA are associated with a decreased blood DC number during AP. Conventional DCs (CDCs) from patients with GPA and MPA in AP exhibited a profound decrease of IL-12/IL-23p40 production after TLR3, 4, or 7/8 stimulation compared to patients in remission and $\mathrm{HC}$, with a return to normal values in RP. TNF $\alpha$ secretion was also affected, with a decrease in cDCs from GPA patients in AP after TLR3 stimulation but an increase after TLR7/8 stimulation. By contrast, the responsiveness of plasmacytoid DCs to TLR7 and 9 was only marginally affected. Finally, we observed that IFN $\gamma$-producing $\mathrm{CD}^{+}{ }^{+} \mathrm{T}$ cell frequency was significantly lower in AP-GPA patients than in $\mathrm{HC}$.

Conclusion: We describe, for the first time, a dysregulated response to TLRs of circulating DCs in AAV patients mostly affecting cDCs that exhibit an unexpected reduced inflammatory cytokine secretion possibly contributing to an altered Th cell response.

Keywords: ANCA-associated vasculitis, dendritic cells, toll-like receptor, IL-12/IL-23p40, dysregulation 


\section{INTRODUCTION}

Antineutrophil cytoplasmic autoantibody (ANCA)-associated vasculitis (AAV) are chronic and systemic autoimmune diseases characterized by small vessels inflammation and necrosis that can involve many organs and tissues (lungs, kidneys, heart, gut, nervous system, skin, etc.). Vascular inflammation, presence or absence of granulomatosis and/or asthma, and ANCA specificity currently help to define three disease entities, namely, granulomatosis with polyangiitis (GPA), microscopic polyangiitis (MPA), and eosinophilic granulomatosis with polyangiitis (EGPA) (1-3). The disease severity is evaluated and followed using the Birmingham Vasculitis Activity Score (BVAS) that takes into account the damage of the different organs affected by the disease (4). Classification and diagnostic of vasculitis are in fact complicated due to heterogeneous nature of these diseases, which comprise a wide range of clinical signs. ANCA are identified by indirect immunofluorescence on fixed neutrophils smears and are mandatory for the diagnosis. ANCA are mostly directed to two neutrophil granule proteins, proteinase 3 (PR3) and myeloperoxidase (MPO). Their specificity is important in clinical practice as PR3-ANCA and MPO-ANCA are strongly associated with GPA and MPA, respectively, whereas the association with EGPA is much less clear $(3,5,6)$. Actually, recent studies led several authors to propose to primarily classify AAV based on ANCA specificity rather than clinical features (7-9). GWAS studies have shown a strongest association of genetic polymorphisms with ANCA specificity rather than with the clinical definition of GPA vs MPA $(10,11)$. Geographical disparities have also been found with PR3-AAV being more prevalent in northwestern Europe and North America, while MPO-AAV is more prevalent in southern Europe, Asia, and the Pacific, possibly due to genetic and environmental factors (8). In fact, this association also extends to some clinical (9) and biological $(12,13)$ parameters.

Pathogenic mechanisms in AAV are not clearly elucidated, but extensive evidence argues for a deleterious role of ANCA as effectors of tissue damage (5). ANCA induce vasculitis by activating circulating primed neutrophils and causing them to penetrate and damage vessel walls by undergoing respiratory burst, degranulation, NETosis, apoptosis, or necrosis. Moreover, ANCA-activated neutrophils also release factors that activate the complement and contribute to inflammation (14). Interestingly, it has been shown that whereas both MPO-ANCA and PR3ANCA can bind and be internalized by endothelial cells, they actually exert different effects: PR3 inducing apoptosis, whereas MPO inducing production of intracellular reactive oxygen species (12). Mechanisms leading to autoimmune response induction and maintenance in AAV are, on the other hand, poorly understood but could be favored by decreased immunoregulatory mechanisms involving regulatory $\mathrm{T}$ and/or $\mathrm{B}$ cells (15-19). More recently, Millet et al. suggested another defect in immunoregulatory mechanisms in GPA by showing that the presence of PR3 on the membrane of apoptotic neutrophils impeded the immunosuppressive effect of apoptotic cell efferocytosis and promoted sustained inflammation (20). The presence of phosphatidylserine-associated PR3 on apoptotic cells generated a proinflammatory microenvironment, which facilitates the differentiation of Th2/Th9 and Th1 $\mathrm{CD}^{+} \mathrm{T}$ cells through the interaction between plasmacytoid dendritic cells (pDCs) and naive T cells (20). The potential role of pathogenic Th subsets in AAV has mostly been studied on GPA and is actually far from clear. Indeed, previous studies have shown an increased frequency of circulating Th1 (21-23), whereas others reported decreased Th1 cells in GPA (24). An increased frequency of Th2 cells in blood (24) and nasal tissues (25) was reported in GPA. Another report showed, by contrast, large numbers of $\mathrm{IFNg}^{+}$but not IL- $4^{+}$cells in nasal tissues in GPA (26). More recently, CD4 ${ }^{+}$ $\mathrm{T}$ cells from GPA patients were also found to exhibit a skewed distribution of Th9 (20). In addition, we recently reported an important decrease in circulating mucosal-associated invariant $\mathrm{T}$ (MAIT) cells in AAV patient that persisted during remission suggesting a role for these innate-like lymphocytes in AAV (27).

Dendritic cells (DCs) are key antigen-presenting cells to naïve $\mathrm{T}$ cells that play critical roles to initiate and control adaptive immune responses $(28,29)$. DCs are heterogeneous and comprise two major populations, conventional DCs (cDCs) and pDCs. DC subsets differ in terms of cytokine production, $\mathrm{T}$ cell stimulation, and in vivo localization (28-31). DCs are activated through sensing exogenous or endogenous ligands that bind pattern recognition receptors, such as toll-like receptors (TLRs), whose expression pattern also differs among DC subsets. Following TLR activation, DCs upregulate costimulatory molecules expression and produce inflammatory cytokines that play crucial roles in $\mathrm{T}$ cell polarization (32), cDCs being major producers of IL-12 and pDCs major producers of type 1 $\operatorname{IFN}(33,34)$.

We previously reported that blood cDCs and pDCs were strongly decreased in AAV patients during flares. This might be related to increased apoptosis of DCs due to systemic inflammation as it was recently shown for pDCs in a mouse model (35), or their recruitment in tissues (17). Supporting this latter hypothesis, we observed an increased expression of the adhesion molecule CD62L on cDCs and even more pronounced on pDCs from AAV patients as compared to DC from healthy controls (HCs) or AAV in remission (17). Very few studies actually analyzed the presence of DCs in AAV lesions. One study showed that CD208 and $\mathrm{CD}_{209^{+}}$cells (presumably cDCs) clustered with T cells in renal biopsies of AAV patients (36), and another one identified DC-LAMP-expressing cells in GPA-granuloma in nasal biopsies (37). A very recent report identified IFN $\alpha$-producing pDCs in close proximity to macrophages and apoptotic neutrophils within lung granuloma lesions in GPA patients (20). Based on these findings, we hypothesized that circulating DCs could have a semi-activated state in AAV patients and be a source of inflammatory cytokines. We therefore analyzed TLR-induced cytokine production by blood DCs from AAV patients using a whole blood (WB) assay and observed that circulating cDCs from GPA and MPA actually displayed a mostly reduced IL-12/IL-23p40 production in response to several TLR ligands, whereas the production of type I IFN by pDCs was preserved overall. Given the central role of DC in polarizing T cells, we also assessed on the same blood samples $\mathrm{T}$ cell subsets frequencies and cytokine production and found a decreased frequency of IFN $\gamma$-producing $\mathrm{CD} 4^{+} \mathrm{T}$ cells. 


\section{MATERIALS AND METHODS}

\section{Patients}

Fourteen HCs and 39 age- and sex-matched patients with AAV, comprising 25 GPA and 14 MPA, were included in this study (Table 1). Acute phase (AP) of AAV was defined by a BVAS $>3$ and remission by a BVAS $=0$ (Table 1 ), according to EULAR activity criteria (38). AP patients were treatment free at time of blood sampling. Patients with flares or in remission had no immunosuppressive drugs for more than 3 months (1 patient) or more than 6 months (19 patients). HCs comprised 14 donors recruited either by the local Blood Bank (EFS Pays de la Loire) or our institution, who were 31-84 years old. Venous blood samples were collected in EDTA and heparin tubes and processed for analysis within $4 \mathrm{~h}$. The study was approved by our local ethical committee (Comité de Protection des Personnes Ouest IV-Nantes), and all patients and HCs provided written informed consent.

\section{WB In Vitro Stimulation Assays Dendritic Cells}

Within a maximum of $4 \mathrm{~h}$ after drawing, $100 \mu \mathrm{l}$ of heparinized WB samples were incubated $4 \mathrm{~h}$ with the following TLR ligands: heat-killed Listeria monocytogenes (HKLM, TLR2-L, $10^{8} \mathrm{HKLM} / \mathrm{ml}$ ), Poly(I:C) (TLR3-L, $100 \mu \mathrm{g} / \mathrm{ml}$ ), CL097 (imidazoquinoline compound, TLR7/8-L, $2 \mu \mathrm{g} / \mathrm{ml}$ ) and CPG ODN2395 [Type C CPG oligonucleotide, TLR9-L, $50 \mu \mathrm{M}$, all obtained from Invivogen (Toulouse, France)], or lipopolysaccharides (from Escherichia coli O26:B6, TLR4-L, 0.1 $\mathrm{\mu g}$ / $\mathrm{ml}$ ) purchased from Sigma-Aldrich (St. Louis, MI, USA). GolgiPlug (BD Biosciences, Le Pont de Claix) was added during the last $3 \mathrm{~h}$ of incubation to inhibit cellular cytokine release. Incubation in medium alone served as a negative control condition.

\section{T Cells}

Within maximum of $4 \mathrm{~h}$ after drawing, 50- $\mu \mathrm{l}$ heparinized WB samples were incubated with PMA (phorbol 12-myristate 13-acetate) and ionomycin both purchased from Sigma-Aldrich (St. Louis, MI, USA) and at $20 \mathrm{ng} / \mathrm{ml}$ and $1 \mu \mathrm{g} / \mathrm{ml}$, respectively. GolgiStop (BD Biosciences) was added during the last $3 \mathrm{~h}$ of incubation to inhibit cellular cytokine release. Incubation in medium alone served as a negative control condition.

\section{Flow Cytometry}

\section{Dendritic Cells}

Dendritic cells were characterized using the six-color flow cytometry assay as we described previously (17). Briefly, $100 \mu \mathrm{l}$ of WB were incubated with the following antibodies: CD45-V500, lineage cocktail1-FITC, HLA-DR-APC-Cy7, CD123-PECy5, all from BD Biosciences and CD11c-PECy7 (Beckman Coulter, Marseille, France). Absolute numbers of DCs were determined using BD Trucount ${ }^{\mathrm{TM}}$ Tubes (BD Biosciences). Samples were analyzed using a BD FacsCanto II analyzer with DIVA software (BD Biosciences, Le Pont de Claix, France). The whole tube was acquired to ensure a minimum of 1,000 events in the $\mathrm{Lin}^{-} \mathrm{HLA}_{-} \mathrm{DR}^{+}$(total DCs) gate for each sample.

\section{T Cell Subsets}

Absolute counts of CD4 and CD8 T cells were determined with BD Multitest ${ }^{\mathrm{TM}}$ CD3/CD8/CD45/CD4 in BD Trucount ${ }^{\mathrm{TM}}$ Tubes. Naïve/memory $T$ cell subsets were identified on WB using CD45-V500, CD3-V421, CD4-PECy5.5, CD8-APC-H7, CD45RA-PECy7, CCR7-PE (BD Biosciences), and with CXCR3FITC, CCR6-APC (Ozyme, St. Quentin-en-Yvelines, France).

\section{Intracellular Cytokine Staining in DCs}

Following WB stimulation with TLR ligands, surface staining was first performed with CD45-V500, Lineage cocktail1-FITC,

TABLE 1 | Patients' clinical and biological features at inclusion.

\begin{tabular}{|c|c|c|c|c|c|}
\hline \multirow[t]{2}{*}{ Characteristics } & \multicolumn{2}{|c|}{ GPA $(N=25)$} & \multicolumn{2}{|c|}{ MPA $(N=14)$} & \multirow{2}{*}{$\mathrm{HC}(N=14)$} \\
\hline & Acute & Remission & Acute & Remission & \\
\hline$n$ & 15 & 10 & 9 & 5 & 14 \\
\hline Mean age (range) & $58(23-82)$ & $59(35-74)$ & $67(41-84)$ & $65(54-81)$ & $49(31-84)$ \\
\hline $\mathrm{M} / \mathrm{F}$ & $8 / 7$ & $4 / 6$ & $5 / 4$ & $2 / 3$ & $7 / 7$ \\
\hline ANCA anti MPO/PR3 & $4 / 11$ & $0 / 10$ & $9 / 0$ & $5 / 0$ & ND \\
\hline BVAS mean (range) & $13(3-23)$ & 0 & $12(6-19)$ & 0 & ND \\
\hline CRP mean (range) (mg/l) & $93(3-267)$ & $4(1-10)$ & $86(20-200)$ & $7(0-28)$ & ND \\
\hline Kidney injury & $8 / 15$ & $4 / 10$ & $5 / 9$ & $3 / 5$ & ND \\
\hline Creatinine level median (range) $(\mu \mathrm{M})$ & $83(41-444)$ & $70(47-140)$ & $195.5(28-420)$ & $96(65-788)$ & ND \\
\hline \multirow[t]{7}{*}{ Last treatment before stop } & AZA: 2 & AZA: 5 & AZA: 0 & AZA: 3 & \\
\hline & MMF: 1 & MMF: 1 & MMF: 0 & MMF: 0 & \\
\hline & MTX: 2 & MTX: 1 & MTX: 0 & MTX: 0 & \\
\hline & RTX: 0 & RTX: 3 & RTX: 0 & RTX: 0 & \\
\hline & Cs: 0 & Cs: 0 & Cs: 1 & Cs: 1 & \\
\hline & CYC: 0 & CYC: 0 & CYC: 1 & CYC: 0 & \\
\hline & None: 10 & None: 0 & None: 7 & None: 1 & \\
\hline Duration of the disease at inclusion (range) (months) & $42.4(0-141)$ & $93.1(50-188)$ & $35.6(0-135)$ & $64(0-67)$ & \\
\hline Relapse/presentation & $5 / 10$ & & $2 / 9$ & & \\
\hline
\end{tabular}

ND, not determined; AZA, azathioprine; MMF, mycophenolate mofetil; MTX, methotrexate; RTX, rituximab; Cs, corticosteroids; CYC, cyclophosphamide; GPA, granulomatosis with polyangiitis; MPA, microscopic polyangiitis; HC, healthy control; ANCA, antineutrophil cytoplasmic autoantibody; BVAS, Birmingham Vasculitis Activity Score. 
HLA-DR-APC-Cy7, CD123-PECy5, and CD11c-PECy7 mAbs. Samples were then lysed, fixed, and permeabilized with Cytofix/ Cytoperm Plus (BD Biosciences) and stained with the following anti-cytokine mAbs TNFo-APC (BD Biosciences), IL-12/ IL-23p40-eFluor450 (eBiosciences, Paris, France), and IFN $\alpha$-PE (MiltenyiBiotec, Paris, France). Samples were analyzed by flow cytometry, and the frequencies of cytokine-producing $\mathrm{CDC}$ and pDC were assessed. The whole tube was acquired to ensure a minimum of 1,000 events in the $\mathrm{Lin}^{-} \mathrm{HLA}^{-\mathrm{DR}^{+}}$(total DCs) gate for each sample.

\section{Intracellular Cytokine Staining in T Cells}

For cytokine production analysis by $\mathrm{T}$ cell subsets, surface staining was first performed with CD45-PERCP, CD3-FITC, and CD8-APC-H7 antibodies (BD Biosciences). Samples were then lysed, fixed, permeabilized, and then stained with IL-17AeFluor660 (eBiosciences), IFN $\gamma$-V450, or IL-5-APC or IL-21-PE (BD Biosciences) antibodies. Samples were analyzed by flow cytometry.

\section{Statistics}

Statistical analyses were performed using GraphPad prism 5.0 software (GraphPad Software, San Diego, CA, USA). Mean comparisons were performed with the non-parametric Kruskal-Wallis test and Dunn's multiple test for post hoc analysis. Differences were defined as statistically significant when ${ }^{\star} p<0.05$.

\section{RESULTS}

\section{Decreased Number of DCs in Both GPA and MPA}

We previously showed that patients with AAV displayed decreased numbers of circulating $\mathrm{cDCs}$ and $\mathrm{pDCs}$ during flares and to a lesser extent in remission phase (RP) (17). Here, we aimed to reproduce these data in a new cohort and assess whether differences could exist between GPA and MPA. Absolute counts of cDCs were significantly decreased in patients with GPA and MPA in AP compared to HCs (Figure 1, ${ }^{* *} p<0.01,{ }^{*} p<0.05$, respectively). There was a trend to return to normal values in RP. A strong decrease of pDC absolute counts was also found in patients with active GPA and MPA (Figure 1, ${ }^{* *} p<0.001$ ), as well as in RP GPA $\left({ }^{*} p<0.05\right)$, but not in RP MPA despite a trend toward lower counts.

\section{Altered Function of $\mathrm{cDCs}$ during AAV Flares}

We then assessed intracellular cytokine production of blood DCs by flow cytometry after stimulation by several TLR ligands with previous detailed method (39). We first investigated the production of the $\mathrm{p} 40$ chain which is shared by IL-12 and IL-23 (Figure 2A), two cytokines playing a critical role in inflammation and Th1 and Th17 CD4 ${ }^{+} \mathrm{T}$ cell polarization, respectively. In AP GPA, we observed a strong decrease of IL-12/IL-23p40 production by $\mathrm{cDCs}$ in response to TLR3-L $\left({ }^{* *} p<0.001\right)$ and more modestly to TLR4-L $\left({ }^{*} p<0.01\right)$ and TLR7/8-L $\left({ }^{* *} p<0.01\right)$ as compared to HC, whereas no difference was detected for RP GPA.

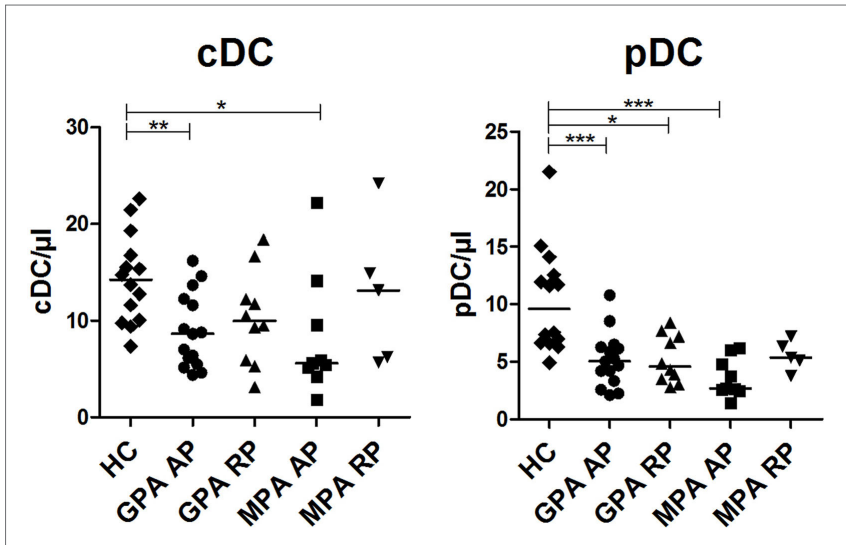

FIGURE 1 | Decreased number of dendritic cells (DCs) in granulomatosis with polyangiitis (GPA) and microscopic polyangiitis (MPA). Conventional DCs (cDCs) and plasmacytoid DCs (pDCs) were enumerated by flow cytometry on whole blood samples from patients with antineutrophil cytoplasmic autoantibody-associated vasculitis and healthy control [HC: $n=14$, GPA-acute phase (AP): $n=15$, GPA-remission phase (RP): $n=10$, MPA-AP: $n=9$, MPA-RP: $n=5]$.

A similar pattern was observed in MPA, but significance was only reached with TLR3 stimulation $\left({ }^{* * *} p<0.001\right)$. By contrast, cDCs from MPA in remission, but not GPA, exhibited an increase production of IL-12p40 upon TLR2 and TLR4 stimulation as compared to HC. As expected, TLR9 ligand did not induce IL-12 production in $\mathrm{cDCs}$.

Concordant with a general alteration $\mathrm{cDC}$ responsiveness in AP GPA patients, TNF $\alpha$ production was also decreased after TLR3 stimulation (Figure 2B) (HC: $\left.{ }^{\star * *} p<0.001\right)$, with a return to a normal level in RP $\left({ }^{*} p<0.05\right)$. The same trend was observed for MPA patients without reaching significance. By contrast, after stimulation with TLR7/8 ligand, cDCs from active GPA and RP MPA patients exhibited increased production of TNF $\alpha$ compared to $\mathrm{HC}\left({ }^{* *} p<0.01,{ }^{*} p<0.05\right)$. However, the production of TNF $\alpha$ after TLR2, 4, and 9 stimulations was not altered.

\section{Production of IFNo by pDCs Is Preserved during Active AAV}

We also investigated if $\mathrm{pDC}$ responsiveness from AAV patients was altered after TLR7/8 or TLR9 stimulation (Figure 3). A slight, but significant, reduction of TNF $\alpha$ production was observed in pDCs from AP GPA patients after stimulation with the TLR7/8 ligand (Figure $3 \mathbf{A},{ }^{* *} p<0.01$ ). We observed that $\mathrm{pDCs}$ from AAV patients displayed a normal response after TLR9 stimulation in both phases of diseases and a normal IFN $\alpha$ production (Figure 3B). Low production of IL-12/IL-23p40 was observed in $\mathrm{pDC}$ from $\mathrm{HC}$ that was further decreased in AP-MPA patients in response to TLR7/8 ligand $\left({ }^{*} p<0.05\right)$ and in AP-GPA after TLR9 stimulation $\left({ }^{*} p<0.01\right)$ (Figure $\left.3 \mathrm{C}\right)$.

\section{Impaired IFN $\gamma$ Production in CD4 ${ }^{+}$ T Cells during AP of GPA}

Considering the decreased induction of IL-12/IL-23p40 in cDCs during AP, we hypothesized this could reverberate on Th1/Th2/ 
Braudeau et al.

DC Dysfunction in AAV Patients

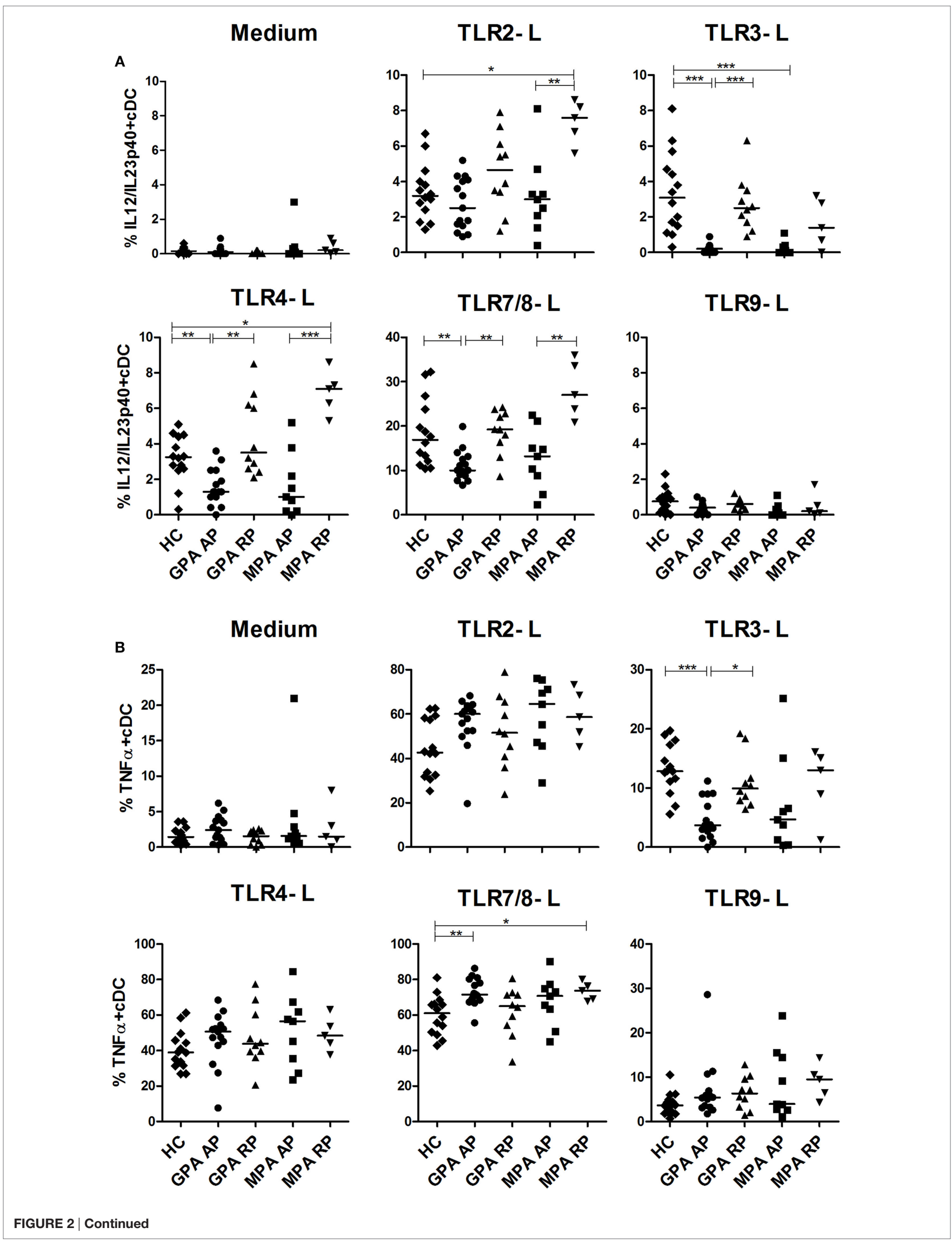

Frontiers in Immunology | www.frontiersin.org

5

\begin{tabular}{l|l|l} 
February 2017 & Volume 8 Article 102
\end{tabular} 
FIGURE 2 | Continued

Altered production of IL-12/IL-23-p40 and TNF $\alpha$ in stimulated conventional dendritic cells (cCDs). Whole blood samples were incubated with medium or

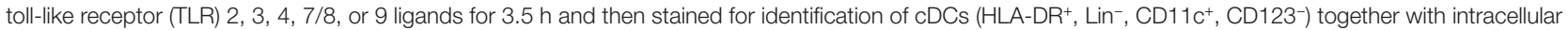
cytokine production IL-12/IL-23p40 (A) and TNF $\alpha$ (B). Healthy control (HC): $n=14$, granulomatosis with polyangiitis (GPA)-acute phase (AP): $n=15$, GPA-remission phase (RP): $n=10$, microscopic polyangiitis (MPA)-AP: $n=9$, MPA-RP: $n=5$.

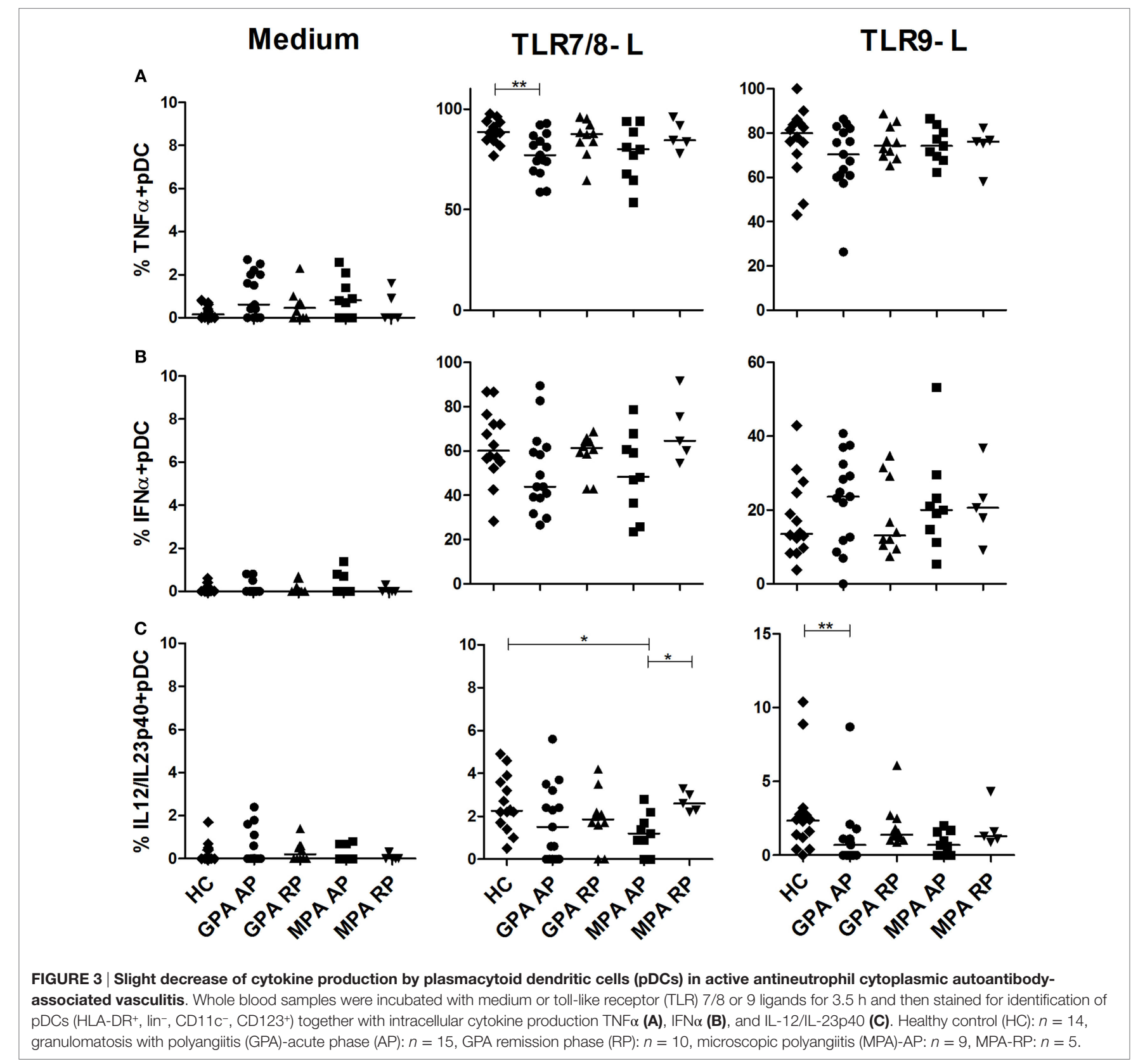

Th17 responses, and we analyzed cytokine production by $\mathrm{T}$ cells after polyclonal stimulation as well as $\%$ of $\mathrm{T}$ cell subsets in our cohort (Figure 4). Interestingly, frequencies of IFN $\gamma$-producing $\mathrm{CD}^{+}$, but not $\mathrm{CD}^{+}, \mathrm{T}$ cells were significantly reduced in AP GPA, but not MPA, as compared to $\mathrm{HC}\left({ }^{\star} p<0.05\right.$, Figure 4A).
A tendency to increased frequencies of IL-17-producing CD4 ${ }^{+} \mathrm{T}$ cells was also observed in GPA only but without reaching statistical significance (Figure 4B). No perturbation in IL-5 and IL-21 production by $\mathrm{CD}^{+}$and $\mathrm{CD}^{+} \mathrm{T}$ cells was observed during AAV (data not shown). 


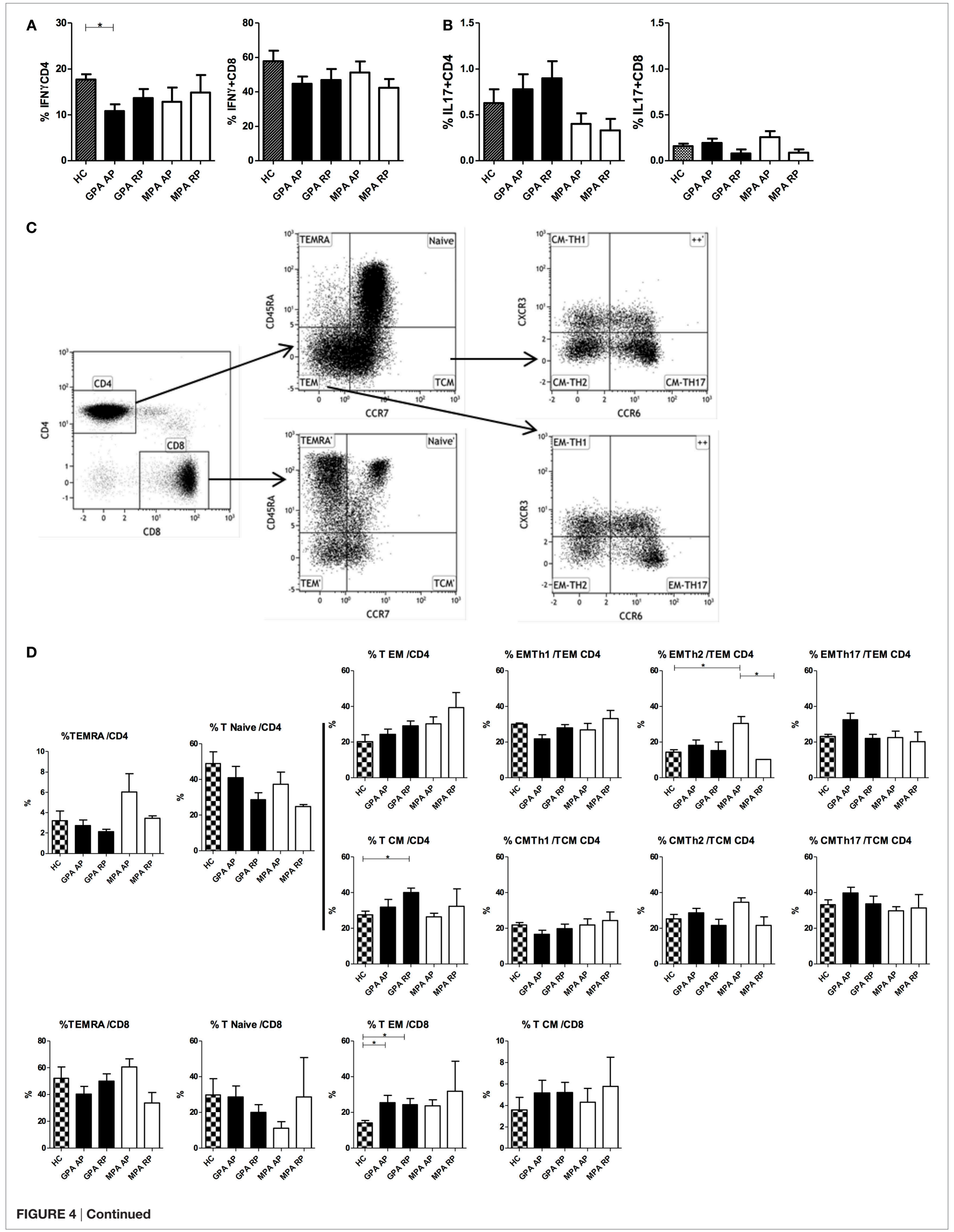




\section{FIGURE 4 | Continued}

Cytokine production and T cell subsets in antineutrophil cytoplasmic autoantibody-associated vasculitis. Intracellular production of IFN $\gamma$ (A) and IL-17 (B) was assessed by flow cytometry in whole blood (WB) in CD4 ${ }^{+}$and $C D 8^{+}$T cells after PMA and ionomycin stimulation in healthy control (HC): $n=10$, granulomatosis with polyangiitis (GPA)-acute phase (AP): $n=15$, GPA-remission phase (RP): $n=10$, microscopic polyangiitis (MPA)-AP: $n=9$, MPA-RP: $n=5$. Frequencies of T cell subsets in WB using flow cytometry (C,D). Gating strategy to identify naïve/memory T cell and Th subsets (C). T cell subsets in HC: $n=7$, GPA-AP: $n=9$, GPA-RP: $n=9$, MPA-AP: $n=7$, MPA-RP: $n=2$ (D). Results are expressed as percentage of positive cells.

Frequencies of Th subsets were also assessed using CXCR3 and CCR6 expression that are useful surface markers for functionally distinct memory T cell subsets: Th17 (CXCR3-CCR6 ${ }^{+}$), Th2 (CXCR3 ${ }^{-} \mathrm{CCR}^{-}{ }^{-}$), Th1/Th17 $\left(\mathrm{CXCR}^{+}{ }^{+} \mathrm{CCR}^{+}\right)$, and Th1 $\left(\mathrm{CXCR}^{+}{ }^{+} \mathrm{CCR}^{-}\right)(40,41)$. The gating strategy is depicted in Figure 4C. No difference was found in naïve $\left(\mathrm{CD} 45 \mathrm{RA}{ }^{+} \mathrm{CCR} 7^{+}\right)$ and TEMRA $\left(\mathrm{CD} 45 \mathrm{RA}^{+} \mathrm{CCR} 7^{-}\right) \mathrm{CD}^{+}$and $\mathrm{CD} 8^{+} \mathrm{T}$ cells between all groups (Figure 4D). In $\mathrm{CD} 4^{+}$effector memory subsets, we found a significant increase of CXCR3 ${ }^{-} \mathrm{CCR}^{-}{ }^{-}$(Th2) T cells in AP MPA $\left({ }^{*} p<0.05\right)$. Central memory $\mathrm{CD} 4^{+} \mathrm{T}$ cells were increased in RP GPA but with no modification of Th1, Th2, and Th17 subsets frequencies. In the CD8 compartment, we observed an increase frequency of effector memory T cells $\left(\mathrm{CD} 45 \mathrm{RA}^{-} \mathrm{CCR} 7^{-}\right)$in GPA patients as compared to $\mathrm{HC}\left({ }^{*} p<0.05\right)$ and a similar trend in MPA, suggestive of increased $\mathrm{CD}^{+} \mathrm{T}$ cell activation in AAV.

\section{DISCUSSION}

Although ANCA play a central role in vascular lesions and inflammation during AAV, the potential role of DCs in regulating autoimmune adaptive responses in these diseases is poorly understood. We first extended our previous findings of a decrease number of blood DC subsets during AAV (17) by showing that this holds true in both GPA and MPA. Given that DCs are major producers of cytokines regulating T-cell activation, we sought to determine whether the capacity of blood DCs to produce cytokines in response to TLR ligands was increased in AAV. We in fact mostly observed a decreased responsiveness of blood cDCs from AAV patients to various TLR ligands. The WB assay we used in this study presents with several advantages. First, it avoids non-specific activation of DCs that is usually associated with isolation procedures. Second, it requires only small volume of blood $(2 \mathrm{ml})$. Third, we previously showed using this assay that pDCs responded only to TLR7/8 and TLR9 ligands by producing mainly IFN $\alpha$ and TNF $\alpha$, but not IL-12p40, whereas cDCs responded to all TLR ligands, but not TLR9, by producing IL-12p40 and TNF $\alpha$, but not IFN $\alpha(39,42)$. These results, which are similar to what has been shown with purified blood cDCs and pDCs with respect to their pattern of response to TLR and frequencies of cytokine-secreting cells (43), led us to consider that this assay mostly assesses the direct effect of TLR ligands on DC subsets. One limit of our assay is however that it assessed $\mathrm{cDC}$ and $\mathrm{pDC}$ responses to single TLR stimulation, and it is likely that these experimental conditions do not measure the maximum capacity of each DC subset to produce cytokines. Indeed, it is well known that optimal secretion of IL-12p70 by human cDCs requires combination of several signals such as a TLR + CD40L (44), TLR + inflammatory cytokines (45), or several TLRs (46).
Circulating DCs have been analyzed in various autoimmune diseases, and their numbers have mostly been reported to be reduced (47). As the presence of both $\mathrm{mDCs}$ and $\mathrm{pDCs}$ have been demonstrated in inflammatory tissues such as skin, synovial fluids, or muscle for instance, the reduction in circulating DC numbers has been proposed to reflect their increased recruitment in these tissues. For instance, in lupus, pDCs are reduced and activated in the blood and are found in large number in some inflammatory tissues $(48,49)$. By contrast, this is much less clear for $\mathrm{mDCs}$ whose migration to inflammatory tissues has not been documented and that are in fact heterogeneous (50). To our knowledge, the responsiveness of circulating mDCs to TLR has not been assessed previously in autoimmune diseases. Our data show that patients with AAV exhibit a profound and rather complex dysregulation of TLR responsiveness. During the AP of AAV, we observed a significant defect of IL-12/IL-23p40 production by cDCs after stimulation with several TLR ligands (TLR3, 4, and $7 / 8$ ), with an apparent return to basal value during remission. This contrasts with previous studies that have shown an increased production of IL-12p70 by activated blood monocytes isolated from active GPA patients as compared to $\operatorname{HD}(23,51)$, which was furthermore normalized by therapy (51). TNF $\alpha$ secretion by cDCs was also affected in AAV, but only after stimulation with TLR 3 or 7/8 ligands. Intriguingly, during active GPA, the frequencies of TNF $\alpha$-producing cDCs after TLR3 stimulation were decreased but were increased after stimulation with TLR7/8 ligand. As cDCs comprise two subsets, namely, CD1c ${ }^{+} \mathrm{cDCs}$ and $\mathrm{CD} 141^{+}$ cDCs (42), it is possible that this dysregulation in TLR responsiveness and cytokine production reflect changes in these $\mathrm{CDC}$ subset frequencies. However, our unpublished and preliminary data indicate that both $\mathrm{CD} 1 \mathrm{c}^{+}$and $\mathrm{CD} 141^{+} \mathrm{cDCs}$ are decreased during AAV flares. These extremely low frequencies of CD141 ${ }^{+}$ cDCs in AAV patients precluded the possibility of assessing their cytokine production using the $\mathrm{WB}$ assay. In contrast to $\mathrm{cDCs}$, pDC functions were only slightly affected with no modification in the main cytokine produced by pDCs, i.e., IFN $\alpha$. Taken together, these results point to a peculiar defect in IL-12p40 production in cDCs during AAV. It remains to be determined whether this will translate in reduced IL-12, IL-23, or both cytokine activities. It will obviously be important to assess the other functions of DCs in AAV patients such as antigen presentation and T cell stimulation activity. However, this is technically challenging due to the frequencies of these cells.

The molecular mechanism for this altered TLR-induced cytokine secretion by cDCs in AAV, especially during the AP, still remains to be understood. One possibility is that this is related to a modulation of TLR expression in DCs, but isolating blood DCs for qPCR experiments would require large volumes of blood and was not technically feasible in this study. As mAb to several 
TLRs are now available, it would be interesting to assess TLR expression by FACS on cDCs in future studies. Of note, Tadema et al. reported an increased expression of TLR2 and TLR4 on monocytes in AAV patients but no difference in TLR expression between patients in AP and RP (52). By contrast, Holle et al. reported no difference in the expression and activation of TLR2, TLR4, and TLR9 on PMNs in GPA compared to HCs (53). Many single-nucleotide polymorphisms (SNPs) in genes that encode TLRs and their signaling molecules have been associated with human disease progression and susceptibility (54). Although Husmann et al. recently reported on the association between four SNPs in TLR9 gene, we observed that the response of $\mathrm{pDC}$ to TLR9 in our assay was normal (55). Another possibility is that intracellular TLR-mediated signaling is altered in DCs from AAV patients. However, the defect we observed involved both MyD88dependent (TLR7/8) and MyD88-independent (TLR3) TLRs, suggesting that proximal signalization is not involved. The fact that a decreased IL-12p40 secretion was observed after TLR3, 4, or $7 / 8$ triggering could suggest a defect in distal NF- $\mathrm{KB}$-dependent gene regulation in $\mathrm{CDCs}$ during AAV (56). Importantly, we only included untreated AAV patients during AP in our study excluding that the observed altered DC functions could be related to immunosuppressive drugs such as corticosteroids that are well known to inhibit the NF- $\mathrm{BB}$ pathway. The role of a soluble factor specific to AAV that would inhibit TLR responsiveness of $\mathrm{cDCs}$, but not pDCs, can not be excluded. In fact, a recent report showed that serum from active AAV patients promoted polarization toward the M2c subtype macrophages, expressing low levels of IL-12 and TNF $\alpha$ and increasing phagocytosis capacity (57).

Using the same assay, we recently reported a reduction in cDC numbers but without IL-12p40 dysregulation in untreated patients suffering from Gaucher disease (39), a form of genetic lysosomal storage disease associated with a strong systemic inflammatory response. Therefore, this suggests that the defect in TLR response we observed in AAV patients is not simply related to systemic inflammation. The numbers of circulating $\mathrm{mDCs}$ and $\mathrm{pDCs}$ were also shown by others to be reduced in the blood of rheumatoid arthritis patients and to inversely correlate with serum CRP levels (58). Although the numbers of $\mathrm{mDCs}$ and pDCs did not correlate with CRP in our AAV patients, it did do with BVAS (data not shown), suggesting again that this decrease is not merely a reflection of systemic inflammation. It would however be important to investigate whether the altered innate function of $\mathrm{cDCs}$ we observed in $\mathrm{AAV}$ is also observed in other autoimmune inflammatory diseases. An important limit of our study is that we only assess the responsiveness of blood DCs and whether this could reflect the function of DCs infiltrating inflammatory tissues is unknown. In spite of an important reduction in circulating $\mathrm{pDC}$ in active AAV, the innate function of these cells appeared well preserved. Supporting this statement, a recent report in GPA patients showed that $\mathrm{pDC}$ are present in inflammatory issues such as the lungs in which they appear to secrete IFN $\alpha$ (20). Interestingly, using a murine model, the same group demonstrated to role for $\mathrm{pDCs}$ in driving pathogenic $\mathrm{T}$ cell responses (20). Regarding cDCs, their presence have been reported in renal (36) and nasal (25) lesions during AAV but whether their capacity to produce cytokines is altered has not been assessed. Investigating the function of these tissues cDCs would therefore be important to understand the significance of our observation in blood DCs. One can hypothesize that this dysregulation of DC responsiveness to TLR is important to reduce inflammatory response. However, by limiting the response to TLR engagement during AP, this could possibly impair immune responses to pathogens in AAV patients and play a role in the reported susceptibility of these patients to some infections $(59,60)$.

The main function of DCs is to stimulate naïve $\mathrm{T}$ cells and drive their differentiation. Interestingly, we observed a reduction in the frequencies of IFN $\gamma$-producing $\mathrm{CD}^{+}{ }^{+} \mathrm{T}$ cells in the blood of AP GPA as compared to $\mathrm{HC}$, confirming a previous report (24). It is tempting to relate this to the defect of IL-12/IL-23p40 observed in DCs, but further investigations are required to demonstrate this link. A tendency to increased frequencies of IL-17-producing $\mathrm{CD}^{+} \mathrm{T}$ cells was observed in GPA, as already found in several studies $(20,61,62)$. Although the potential role of Th17 cells in AAV remains to be demonstrated, recent data indicate that Th17 cells are important effector cells in humoral autoimmune diseases (63). T cell subset analysis showed also discrete modifications regarding the proportion of naïve vs memory $\mathrm{CD} 4^{+} \mathrm{T}$ cells that actually confirm previous studies showing a persistent expansion of $\mathrm{CD}^{+}$effector memory $\mathrm{T}$ cells, with a reciprocal decrease in naïve $\mathrm{CD}^{+} \mathrm{T}$ cells in $\mathrm{AAV}$ patients $(64,65)$. Accordingly, infiltrating $\mathrm{T}$ cells in lung lesions and glomeruli were shown to consist mainly of $\mathrm{CD}^{+} \mathrm{T}$ cells with a memory phenotype (66, 67). However, an important limit of our study is that we analyzed polyclonal and not antigen-specific responses of $\mathrm{T}$ cells.

Our study also indicates that GPA and MPA exhibit some subtle difference regarding the function of DC and the frequencies of T cells. Both GPA and MPA are associated with an important decrease in circulating $\mathrm{cDCs}$ and $\mathrm{pDCs}$ during flares and very similar dysregulation of TLR responsiveness with a decrease response to TLR3, 4, and 7/8. However, during remission, DCs from MPA, but not GPA, patients exhibited an increased IL-12p40 production upon TLR2 and TLR4 stimulation suggesting a hyperactivated state. As TLR2 and 4 are mostly involved in the recognition of Gram+ and Gram- bacterial wall, it will be interesting to address the role of this apparent increase DC responsiveness in the absence of role of Staphylococcus aureus carriage for MPA relapses $(68,69)$. Another difference was the increase frequency of "Th2" effector memory cells in MPA vs HC and GPA during AP. It should be noted that classifying our patients according to their ANCA specificity rather than to the clinical syndrome did not change the results of our study as all MPA patients had MPO-ANCA and only 5 out of 25 GPA patients had MPO-ANCA rather than PR3-ANCA.

In summary, we describe for the first time, a dysregulated response to TLRs of blood DCs in AAV patients as evidenced by altered cytokine production, with previously unreported defect of IL-12/IL-23p40 pathway. Together with our recent report on the persistent decrease of MAIT cells in the same patients (27), these results point to a role for altered innate immune responses in the pathogenesis of AAV. How this impacts on the autoantigen-specific and pathogenic immune response remains to be determined. 


\section{ETHICS STATEMENT}

This study was carried out in accordance with the recommendations of our Institutional Review Board (CPP OUEST IV) with written informed consent from all subjects. All the subjects gave written informed consent in accordance with the Declaration of Helsinki.

\section{AUTHOR CONTRIBUTIONS}

$\mathrm{CB}$ and $\mathrm{AN}$ participated in the design of the study, carried out the experiments, and prepared the manuscript. $\mathrm{MH}, \mathrm{MR}$, and JM participated to the conception of the study, contributed to the discussion, and reviewed the manuscript. KA, AB, SG, CT,

\section{REFERENCES}

1. Jennette JC, Falk RJ, Bacon PA, Basu N, Cid MC, Ferrario F, et al. 2012 revised International Chapel Hill Consensus Conference Nomenclature of Vasculitides. Arthritis Rheum (2013) 65:1-11. doi:10.1002/art.37715

2. Mahr A, de Menthon M. Classification and classification criteria for vasculitis: achievements, limitations and prospects. Curr Opin Rheumatol (2015) 27:1-9. doi:10.1097/BOR.0000000000000134

3. Hellmich B, Flossmann O, Gross WL, Bacon P, Cohen-Tervaert JW, Guillevin L, et al. EULAR recommendations for conducting clinical studies and/or clinical trials in systemic vasculitis: focus on anti-neutrophil cytoplasm antibody-associated vasculitis. Ann Rheum Dis (2007) 66:605-17. doi:10.1136/ard.2006.062711

4. Mukhtyar C, Lee R, Brown D, Carruthers D, Dasgupta B, Dubey S, et al. Modification and validation of the Birmingham Vasculitis Activity Score (version 3). Ann Rheum Dis (2009) 68:1827-32. doi:10.1136/ard.2008.101279

5. Jennette JC, Falk RJ. Pathogenesis of antineutrophil cytoplasmic autoantibody-mediated disease. Nat Rev Rheumatol (2014) 10:463-73. doi:10.1038/nrrheum.2014.103

6. Kallenberg CG. Usefulness of antineutrophil cytoplasmic autoantibodies in diagnosing and managing systemic vasculitis. Curr Opin Rheumatol (2015) 28:8-14. doi:10.1097/BOR.0000000000000233

7. Watts RA, Scott DG. ANCA vasculitis: to lump or split? Why we should study MPA and GPA separately. Rheumatology (Oxford) (2012) 51:2115-7. doi:10.1093/rheumatology/kes230

8. Millet A, Pederzoli-Ribeil M, Guillevin L, Witko-Sarsat V, Mouthon L. Antineutrophil cytoplasmic antibody-associated vasculitides: is it time to split up the group? Ann Rheum Dis (2013) 72:1273-9. doi:10.1136/ annrheumdis-2013-203255

9. Hilhorst M, van Paassen P, Tervaert JW; Limburg Renal Registry. Proteinase 3-ANCA vasculitis versus myeloperoxidase-ANCA vasculitis. JAm Soc Nephrol (2015) 26:2314-27. doi:10.1681/ASN.2014090903

10. Lyons PA, Rayner TF, Trivedi S, Holle JU, Watts RA, Jayne DR, et al. Genetically distinct subsets within ANCA-associated vasculitis. N Engl J Med (2012) 367:214-23. doi:10.1056/NEJMoa1108735

11. Xie G, Roshandel D, Sherva R, Monach PA, Lu EY, Kung T, et al. Association of granulomatosis with polyangiitis (Wegener's) with HLA-DPB1*04 and SEMA6A gene variants: evidence from genome-wide analysis. Arthritis Rheum (2013) 65:2457-68. doi:10.1002/art.38036

12. Yang JJ, Preston GA, Pendergraft WF, Segelmark M, Heeringa P, Hogan SL, et al. Internalization of proteinase 3 is concomitant with endothelial cell apoptosis and internalization of myeloperoxidase with generation of intracellular oxidants. Am J Pathol (2001) 158:581-92. doi:10.1016/S0002-9440(10) 64000-X

13. Le Roux S, Pepper RJ, Dufay A, Neel M, Meffray E, Lamande N, et al. Elevated soluble Flt1 inhibits endothelial repair in PR3-ANCA-associated vasculitis. J Am Soc Nephrol (2012) 23:155-64. doi:10.1681/ASN.2010080858
MA, NS, and CH performed experiments. RJ designed the study, supervised the project, and wrote the final manuscript.

\section{FUNDING}

This work was supported by a grant from the Direction de la Recherche Clinique et de l'Innovation (DRCI), CHU Nantes (\#BRD/09/06) to RJ. The CIMNA was supported by the IMBIO-DC program supported by the "Région des Pays de la Loire" and the LabEX IGO project supported by the "Investissements d'Avenir" program through the "Agence Nationale de la Recherche" (ANR11-LABX-0016-01). AN was supported by the Société Nationale Française de Médecine Interne (Bourse Marcel Simon).
14. Xiao H, Schreiber A, Heeringa P, Falk RJ, Jennette JC. Alternative complement pathway in the pathogenesis of disease mediated by anti-neutrophil cytoplasmic autoantibodies. Am J Pathol (2007) 170:52-64. doi:10.2353/ ajpath.2007.060573

15. Morgan MD, Day CJ, Piper KP, Khan N, Harper L, Moss PA, et al. Patients with Wegener's granulomatosis demonstrate a relative deficiency and functional impairment of T-regulatory cells. Immunology (2010) 130:64-73. doi:10.1111/j.1365-2567.2009.03213.x

16. Free ME, Bunch DO, McGregor JA, Jones BE, Berg EA, Hogan SL, et al. Patients with antineutrophil cytoplasmic antibody-associated vasculitis have defective Treg cell function exacerbated by the presence of a suppressionresistant effector cell population. Arthritis Rheum (2013) 65:1922-33. doi:10.1002/art.37959

17. Rimbert M, Hamidou M, Braudeau C, Puechal X, Teixeira L, Caillon H, et al. Decreased numbers of blood dendritic cells and defective function of regulatory $\mathrm{T}$ cells in antineutrophil cytoplasmic antibody-associated vasculitis. PLoS One (2011) 6:e18734. doi:10.1371/journal.pone. 0018734

18. Aybar LT, McGregor JG, Hogan SL, Hu Y, Mendoza CE, Brant EJ, et al. Reduced CD5(+) CD24(hi) CD38(hi) and interleukin-10(+) regulatory B cells in active anti-neutrophil cytoplasmic autoantibody-associated vasculitis permit increased circulating autoantibodies. Clin Exp Immunol (2015) 180:178-88. doi:10.1111/cei.12483

19. Bunch DO, McGregor JG, Khandoobhai NB, Aybar LT, Burkart ME, Hu $\mathrm{Y}$, et al. Decreased CD5(+) B cells in active ANCA vasculitis and relapse after rituximab. Clin JAm Soc Nephrol (2013) 8:382-91. doi:10.2215/ CJN.03950412

20. Millet A, Martin KR, Bonnefoy F, Saas P, Mocek J, Alkan M, et al. Proteinase 3 on apoptotic cells disrupts immune silencing in autoimmune vasculitis. J Clin Invest (2015) 125:4107-21. doi:10.1172/JCI78182

21. Chavele KM, Shukla D, Keteepe-Arachi T, Seidel JA, Fuchs D, Pusey CD, et al. Regulation of myeloperoxidase-specific $\mathrm{T}$ cell responses during disease remission in antineutrophil cytoplasmic antibody-associated vasculitis: the role of Treg cells and tryptophan degradation. Arthritis Rheum (2010) 62:1539-48. doi:10.1002/art.27403

22. Csernok E, Trabandt A, Muller A, Wang GC, Moosig F, Paulsen J, et al. Cytokine profiles in Wegener's granulomatosis: predominance of type 1 (Th1) in the granulomatous inflammation. Arthritis Rheum (1999) 42:742-50. doi:10.1002/1529-0131(199904)42:4<742::AID-ANR18>3.3.CO;2-9

23. Ludviksson BR, Sneller MC, Chua KS, Talar-Williams C, Langford CA, Ehrhardt RO, et al. Active Wegener's granulomatosis is associated with HLA-DR+ CD4+ T cells exhibiting an unbalanced Th1-type T cell cytokine pattern: reversal with IL-10. J Immunol (1998) 160:3602-9.

24. Abdulahad WH, Stegeman CA, Limburg PC, Kallenberg CG. Skewed distribution of Th17 lymphocytes in patients with Wegener's granulomatosis in remission. Arthritis Rheum (2008) 58:2196-205. doi:10.1002/ art.23557 
25. Balding CE, Howie AJ, Drake-Lee AB, Savage CO. Th2 dominance in nasal mucosa in patients with Wegener's granulomatosis. Clin Exp Immunol (2001) 125:332-9. doi:10.1046/j.1365-2249.2001.125002332.x

26. Muller A, Trabandt A, Gloeckner-Hofmann K, Seitzer U, Csernok E, Schonermarck U, et al. Localized Wegener's granulomatosis: predominance of CD26 and IFN-gamma expression. J Pathol (2000) 192:113-20. doi:10.1002/1096-9896(2000)9999:9999<::AID-PATH656>3.3.CO;2-D

27. Braudeau C, Amouriaux K, Neel A, Herbreteau G, Salabert N, Rimbert M, et al. Persistent deficiency of circulating mucosal-associated invariant $\mathrm{T}$ (MAIT) cells in ANCA-associated vasculitis. J Autoimmun (2016) 70:73-9. doi:10.1016/j.jaut.2016.03.015

28. Banchereau J, Steinman RM. Dendritic cells and the control of immunity. Nature (1998) 392:245-52. doi:10.1038/32588

29. Kapsenberg ML. Dendritic-cell control of pathogen-driven T-cell polarization. Nat Rev Immunol (2003) 3:984-93. doi:10.1038/nri1246

30. Sozzani S, Allavena P, Vecchi A, Mantovani A. Chemokines and dendritic cell traffic. J Clin Immunol (2000) 20:151-60. doi:10.1023/A:1006659211340

31. Iwasaki A, Medzhitov R. Toll-like receptor control of the adaptive immune responses. Nat Immunol (2004) 5:987-95. doi:10.1038/ni1112

32. Jin B, Sun T, Yu XH, Yang YX, Yeo AE. The effects of TLR activation on T-cell development and differentiation. Clin Dev Immunol (2012) 2012:836485. doi:10.1155/2012/836485

33. Macatonia SE, Hosken NA, Litton M, Vieira P, Hsieh CS, Culpepper JA, et al. Dendritic cells produce IL-12 and direct the development of Th1 cells from naive CD4+ T cells. J Immunol (1995) 154:5071-9.

34. Colonna M, Trinchieri G, Liu YJ. Plasmacytoid dendritic cells in immunity. Nat Immunol (2004) 5:1219-26. doi:10.1038/ni1141

35. Mossu A, Daoui A, Bonnefoy F, Aubergeon L, Saas P, Perruche S. Plasmacytoid dendritic cells die by the CD8 T cell-dependent perforin pathway during acute nonviral inflammation. J Immunol (2016) 197:1672-82. doi:10.4049/ jimmunol.1501875

36. Wilde B, van Paassen P, Damoiseaux J, Heerings-Rewinkel P, van Rie H, Witzke O, et al. Dendritic cells in renal biopsies of patients with ANCAassociated vasculitis. Nephrol Dial Transplant (2009) 24:2151-6. doi:10.1093/ ndt/gfp019

37. Capraru D, Muller A, Csernok E, Gross WL, Holl-Ulrich K, Northfield J, et al. Expansion of circulating NKG2D+ effector memory T-cells and expression of NKG2D-ligand MIC in granulomatous lesions in Wegener's granulomatosis. Clin Immunol (2008) 127:144-50. doi:10.1016/j.clim.2007.12.004

38. Basu N, Watts R, Bajema I, Baslund B, Bley T, Boers M, et al. EULAR points to consider in the development of classification and diagnostic criteria in systemic vasculitis. Ann Rheum Dis (2010) 69:1744-50. doi:10.1136/ard.2009. 119032

39. Braudeau C, Graveleau J, Rimbert M, Neel A, Hamidou M, Grosbois B, et al. Altered innate function of plasmacytoid dendritic cells restored by enzyme replacement therapy in Gaucher disease. Blood Cells Mol Dis (2013) 50:281-8. doi:10.1016/j.bcmd.2013.01.001

40. Rivino L, Messi M, Jarrossay D, Lanzavecchia A, Sallusto F, Geginat J. Chemokine receptor expression identifies Pre-T helper (Th)1, Pre-Th2, and nonpolarized cells among human CD4+ central memory T cells. J Exp Med (2004) 200:725-35. doi:10.1084/jem.20040774

41. Acosta-Rodriguez EV, Rivino L, Geginat J, Jarrossay D, Gattorno M, Lanzavecchia A, et al. Surface phenotype and antigenic specificity of human interleukin 17-producing T helper memory cells. Nat Immunol (2007) 8:639-46. doi:10.1038/ni1467

42. Hemont C, Neel A, Heslan M, Braudeau C, Josien R. Human blood mDC subsets exhibit distinct TLR repertoire and responsiveness. J Leukoc Biol (2013) 93:599-609. doi:10.1189/jlb.0912452

43. Kadowaki N, Ho S, Antonenko S, Malefyt RW, Kastelein RA, Bazan F, et al. Subsets of human dendritic cell precursors express different toll-like receptors and respond to different microbial antigens. J Exp Med (2001) 194:863-9. doi:10.1084/jem.194.6.863

44. Poulin LF, Salio M, Griessinger E, Anjos-Afonso F, Craciun L, Chen JL, et al. Characterization of human DNGR-1+ BDCA3+ leukocytes as putative equivalents of mouse CD8alpha+ dendritic cells. J Exp Med (2010) 207:1261-71. doi:10.1084/jem.20092618

45. Nizzoli G, Krietsch J, Weick A, Steinfelder S, Facciotti F, Gruarin P, et al. Human CD1c+ dendritic cells secrete high levels of IL-12 and potently prime cytotoxic T-cell responses. Blood (2013) 122:932-42. doi:10.1182/ blood-2013-04-495424

46. Napolitani G, Rinaldi A, Bertoni F, Sallusto F, Lanzavecchia A. Selected toll-like receptor agonist combinations synergistically trigger a $\mathrm{T}$ helper type 1-polarizing program in dendritic cells. Nat Immunol (2005) 6:769-76. doi:10.1038/ni1223

47. Coutant F, Miossec P. Altered dendritic cell functions in autoimmune diseases: distinct and overlapping profiles. Nat Rev Rheumatol (2016) 12:703-15. doi:10.1038/nrrheum.2016.147

48. Fiore N, Castellano G, Blasi A, Capobianco C, Loverre A, Montinaro V, et al. Immature myeloid and plasmacytoid dendritic cells infiltrate renal tubulointerstitium in patients with lupus nephritis. Mol Immunol (2008) 45:259-65. doi:10.1016/j.molimm.2007.04.029

49. Tucci M, Quatraro C, Lombardi L, Pellegrino C, Dammacco F, Silvestris F. Glomerular accumulation of plasmacytoid dendritic cells in active lupus nephritis: role of interleukin-18. Arthritis Rheum (2008) 58:251-62. doi:10.1002/art.23186

50. Worbs T, Hammerschmidt SI, Forster R. Dendritic cell migration in health and disease. Nat Rev Immunol (2017) 17:30-48. doi:10.1038/nri. 2016.116

51. Lamprecht P, Kumanovics G, Mueller A, Csernok E, Komocsi A, Trabandt A, et al. Elevated monocytic IL-12 and TNF-alpha production in Wegener's granulomatosis is normalized by cyclophosphamide and corticosteroid therapy. Clin Exp Immunol (2002) 128:181-6. doi:10.1046/j.1365-2249.2002. 01801.x

52. Tadema H, Abdulahad WH, Stegeman CA, Kallenberg CG, Heeringa P. Increased expression of toll-like receptors by monocytes and natural killer cells in ANCA-associated vasculitis. PLoS One (2011) 6:e24315. doi:10.1371/ journal.pone.0024315

53. Holle JU, Windmoller M, Lange C, Gross WL, Herlyn K, Csernok E. Toll-like receptor TLR2 and TLR9 ligation triggers neutrophil activation in granulomatosis with polyangiitis. Rheumatology (Oxford) (2013) 52:1183-9. doi:10.1093/ rheumatology/kes415

54. Tartey S, Takeuchi O. Pathogen recognition and toll-like receptor targeted therapeutics in innate immune cells. Int Rev Immunol (2017) 1-17. doi:10.1080/08830185.2016.1261318

55. Husmann CA, Holle JU, Moosig F, Mueller S, Wilde B, Cohen Tervaert JW, et al. Genetics of toll like receptor 9 in ANCA associated vasculitides. Ann Rheum Dis (2014) 73:890-6. doi:10.1136/annrheumdis-2012-202803

56. Kawai T, Akira S. The role of pattern-recognition receptors in innate immunity: update on toll-like receptors. Nat Immunol (2010) 11:373-84. doi:10.1038/ ni. 1863

57. Ohlsson SM, Linge CP, Gullstrand B, Lood C, Johansson A, Ohlsson S, et al. Serum from patients with systemic vasculitis induces alternatively activated macrophage M2c polarization. Clin Immunol (2014) 152:10-9. doi:10.1016/ j.clim.2014.02.016

58. Jongbloed SL, Lebre MC, Fraser AR, Gracie JA, Sturrock RD, Tak PP, et al. Enumeration and phenotypical analysis of distinct dendritic cell subsets in psoriatic arthritis and rheumatoid arthritis. Arthritis Res Ther (2006) 8:R15. doi:10.1186/ar1864

59. Richter AG, Stockley RA, Harper L, Thickett DR. Pulmonary infection in Wegener granulomatosis and idiopathic pulmonary fibrosis. Thorax (2009) 64:692-7. doi:10.1136/thx.2008.110445

60. Fillatre P, Decaux O, Jouneau S, Revest M, Gacouin A, Robert-Gangneux F, et al. Incidence of Pneumocystis jiroveci pneumonia among groups at risk in HIV-negative patients. Am J Med (2014) 127(1242):e1211-47. doi:10.1016/ j.amjmed.2014.07.010

61. Abdulahad WH, Stegeman CA, Limburg PC, Kallenberg CG. CD4-positive effector memory $\mathrm{T}$ cells participate in disease expression in ANCAassociated vasculitis. Ann N Y Acad Sci (2007) 1107:22-31. doi:10.1196/ annals. 1381.003

62. Nogueira E, Hamour S, Sawant D, Henderson S, Mansfield N, Chavele KM, et al. Serum IL-17 and IL-23 levels and autoantigen-specific Th17 cells are elevated in patients with ANCA-associated vasculitis. Nephrol Dial Transplant (2010) 25:2209-17. doi:10.1093/ndt/gfp783

63. Martin JC, Baeten DL, Josien R. Emerging role of IL-17 and Th17 cells in systemic lupus erythematosus. Clin Immunol (2014) 154:1-12. doi:10.1016/ j.clim.2014.05.004 
64. Abdulahad WH, van der Geld YM, Stegeman CA, Kallenberg CG. Persistent expansion of CD4+ effector memory T cells in Wegener's granulomatosis. Kidney Int (2006) 70:938-47. doi:10.1038/sj.ki.5001670

65. Marinaki S, Neumann I, Kalsch AI, Grimminger P, Breedijk A, Birck R, et al. Abnormalities of CD4 T cell subpopulations in ANCA-associated vasculitis. Clin Exp Immunol (2005) 140:181-91. doi:10.1111/j.1365-2249.2005. 02731.x

66. Lamprecht P, Erdmann A, Mueller A, Csernok E, Reinhold-Keller E, HollUlrich $\mathrm{K}$, et al. Heterogeneity of CD4 and CD8+ memory T cells in localized and generalized Wegener's granulomatosis. Arthritis Res Ther (2003) 5:R25-31. doi:10.1186/ar610

67. Wilde B, Dolff S, Cai X, Specker C, Becker J, Totsch M, et al. CD4+CD25+ T-cell populations expressing CD134 and GITR are associated with disease activity in patients with Wegener's granulomatosis. Nephrol Dial Transplant (2009) 24:161-71. doi:10.1093/ndt/gfn461

68. Stegeman CA, Tervaert JW, Sluiter WJ, Manson WL, de Jong PE, Kallenberg CG. Association of chronic nasal carriage of Staphylococcus aureus and higher relapse rates in Wegener granulomatosis. Ann Intern Med (1994) 120:12-7. doi:10.7326/0003-4819-120-1-199401010-00003

69. van Timmeren MM, Heeringa P, Kallenberg CG. Infectious triggers for vasculitis. Curr Opin Rheumatol (2014) 26:416-23. doi:10.1097/BOR. 0000000000000068

Conflict of Interest Statement: The authors declare that the research was conducted in the absence of any commercial or financial relationships that could be construed as a potential conflict of interest.

Copyright (C) 2017 Braudeau, Néel, Amouriaux, Martin, Rimbert, Besançon, Giraudet, Terrien, Aliaga, Salabert-Le Guen, Hémont, Hamidou and Josien. This is an openaccess article distributed under the terms of the Creative Commons Attribution License (CC BY). The use, distribution or reproduction in other forums is permitted, provided the original author(s) or licensor are credited and that the original publication in this journal is cited, in accordance with accepted academic practice. No use, distribution or reproduction is permitted which does not comply with these terms. 